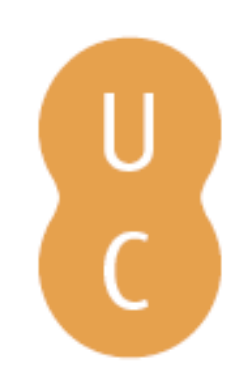

\title{
nommalina
}

\section{Caracterização das instabilizações de taludes de escavação no Areeiro, Coimbra,} Portugal

\author{
Autor(es): $\quad$ QuintaFerreira, M.; Andrade, P. S.; Lemos, L. L.; Saraiva, A. A. \\ Publicado por: Imprensa da Universidade de Coimbra \\ URL \\ persistente: URI:http://hdl.handle.net/10316.2/31493 \\ DOI: $\quad$ DOI:http://dx.doi.org/10.14195/978-989-26-0531-9_46 \\ Accessed : $\quad$ 26-Apr-2023 16:04:18
}

A navegação consulta e descarregamento dos títulos inseridos nas Bibliotecas Digitais UC Digitalis, UC Pombalina e UC Impactum, pressupõem a aceitação plena e sem reservas dos Termos e Condições de Uso destas Bibliotecas Digitais, disponíveis em https://digitalis.uc.pt/pt-pt/termos.

Conforme exposto nos referidos Termos e Condições de Uso, o descarregamento de títulos de acesso restrito requer uma licença válida de autorização devendo o utilizador aceder ao(s) documento(s) a partir de um endereço de IP da instituição detentora da supramencionada licença.

Ao utilizador é apenas permitido o descarregamento para uso pessoal, pelo que o emprego do(s) título(s) descarregado(s) para outro fim, designadamente comercial, carece de autorização do respetivo autor ou editor da obra.

Na medida em que todas as obras da UC Digitalis se encontram protegidas pelo Código do Direito de Autor e Direitos Conexos e demais legislação aplicável, toda a cópia, parcial ou total, deste documento, nos casos em que é legalmente admitida, deverá conter ou fazer-se acompanhar por este aviso.

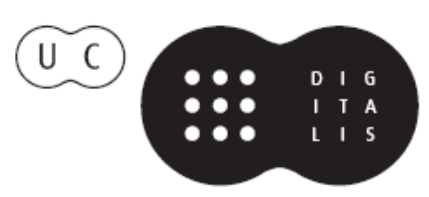



46

\title{
CARACTERIZAÇÃO DAS INSTABILIZAÇÓES DE TALUDES DE ESCAVAÇẤO NO AREEIRO, COIMBRA, PORTUGAL
}

\author{
CHARACTERIZATION OF THE CUT SLOPES FAILURES \\ IN AREEIRO, COIMBRA, PORTUGAL
}

M. Quinta-Ferreira ${ }^{1}$, P. S. Andrade²; L. L. Lemos 33 , A. A. Saraiva ${ }^{4}$

\begin{abstract}
Resumo - Procedeu-se à análise de diferentes situaçôes de instabilidade de taludes de escavaçáo que se verificaram nos "Grés de Silves" na zona do Areeiro em Coimbra. A reduzida inclinação dos planos de estratificação que originaram a instabilizaçáo, a presença de camadas de pelitos acinzentados e a ocorrência de precipitação intensa constituem os aspetos mais marcantes das instabilizaçóes. O estudo de campo e de laboratório permitiu concluir que a resistência dos pelitos decresce progressivamente, sendo influenciada essencialmente pela descompressão e alteração, desenvolvendo-se condições favoráveis à instabilização quando aumenta a pressão da água.
\end{abstract}

Palavras-chave - Deslizamentos; Triásico; Pelitos; Alteração; Coimbra.

Abstract - Various instability situations on excavation slopes that occurred in the "Grés de Silves" in the Areeiro area, Coimbra, are evaluated. The reduced dip angle of the bedding planes that led to instability, the presence of the grey mudstone layers and the occurrence of heavy precipitation are the most striking aspects of the failures. The field and laboratory study concluded that the strength of the mudstones decreases progressively in time and is mainly influenced by decompression and weathering, creating conditions favourable to instability when pore water pressure increases.

Keywords - Landslides, Triasic, Mudstones, Weathering, Coimbra.

124 Departamento de Ciências da Terra. Centro de Geociências. Largo Marquês de Pombal. Universidade de Coimbra. 3000-272 Coimbra. Portugal; ${ }^{1}$ mqf@dct.uc.pt, ${ }^{2}$ pandrade@dct.uc.pt, ${ }^{4}$ asaraiva@dct.uc.pt

${ }^{3}$ Departamento de Engenharia Civil. Centro de Engenharia Civil. Polo II. Universidade de Coimbra. Rua Luís Reis dos Santos.3030-788 Coimbra; llemos@dec.uc.pt 


\section{1 - Introdução}

Desde o ano de 2004 verificaram-se várias situaçóes de instabilização na zona do Areeiro, em Coimbra, apresentando algumas semelhanças geométricas, mas condiçóes de instabilização diferenciadas. De modo a definir as causas destas instabilizaçóes efetuou-se um estudo de campo, com a recolha de informação dos vários episódios de instabilização e, posteriormente realizaram-se ensaios de laboratório. A partir do trabalho desenvolvido procurou-se entender as causas das instabilizações, em situaçóes geológicas que não faziam antever a ocorrência de deslizamentos, devido à reduzida inclinação das camadas, com cerca de $15^{\circ}$ a $16^{\circ}$.

A primeira instabilização de que temos registo ocorreu em Março de 2004, durante os trabalhos de escavação para a construção da estrada a nascente da Escola do Areeiro. Tratou-se de uma pequena escavação com alguns metros de altura máxima, numa extensão de cerca de $100 \mathrm{~m}$ segundo a diretriz da estrada (Fig. 1-a). Em Dezembro do ano seguinte, em 2005, ocorreu a segunda instabilizaçáo, mas agora a oeste da Escola do Areeiro (Fig. 1-b). Passados alguns meses, em Março de 2006, ocorreu nova instabilização após a escavação resultante da preparação da plataforma para a urbanização da Quinta do Areeiro, durante a construção do muro de suporte em gabiōes, que pretendia estabilizar o talude escavado. Esta instabilização foi limitada superiormente por uma falha subvertical, que limitou o desenvolvimento da rotura, evitando que chegasse até à habitação na parte superior do terreno (Fig. 1-c). No final de 2007 verificou-se nova instabilizaçáo por baixo da escola do Areeiro, mas com menores dimensóes que a ocorrida anteriormente. Em Abril de 2010 ocorreu uma instabilização no talude de escavação da rotunda do Areeiro (Fig. 1-d). Em Maio do ano seguinte houve mais uma instabilização na rotunda do Areeiro, dando continuidade para norte à instabilização anterior.

\section{2 - Contribuição da geologia para as instabilizaçóes}

A geologia local é constituída por materiais sedimentares da unidade dos "Grés de Silves" datados do Triásico (PALAIN, 1976; AZERÊDO et al., 2003; SOARES et al., 2007), sobrepondo-se aos xistos Proterozóicos da unidade designada como série negra. $\mathrm{Na}$ área estudada observam-se arenitos e conglomerados de cores avermelhadas cuja origem está relacionada com a deposição fluvial, também se regista a presença de níveis pelíticos de tonalidades acizentadas, cuja formação está associada à sedimentação lacustre de profundidades reduzidas (MIRANDA et al., 2010).

Anteriormente à recente intervenção humana no terreno, os processos da geodinâmica externa (alteração, erosão e transporte), modelaram a geomorfologia do terreno, conferindo um declive mais suave à vertente do lado do Areeiro, em relação à Quinta da Portela, do lado oeste do vale, dado que a estrutura geológica inclina suavemente para oeste. Na Fig. 2 apresenta-se um perfil do terreno segundo um alinhamento aproximadamente EW, ilustrando o declive dos dois lados do vale, sendo evidente o baixo declive do lado do Areeiro, onde foram registadas as instabilizações. 


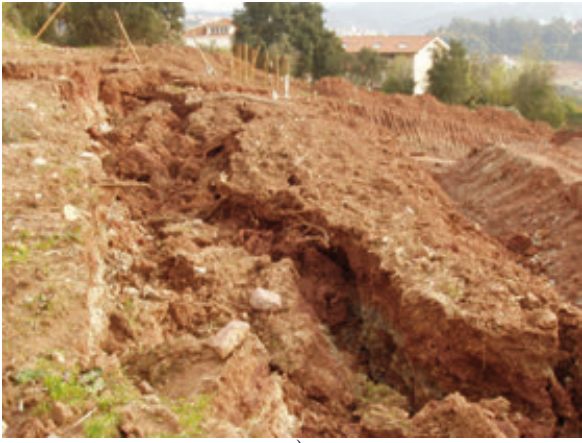

a)

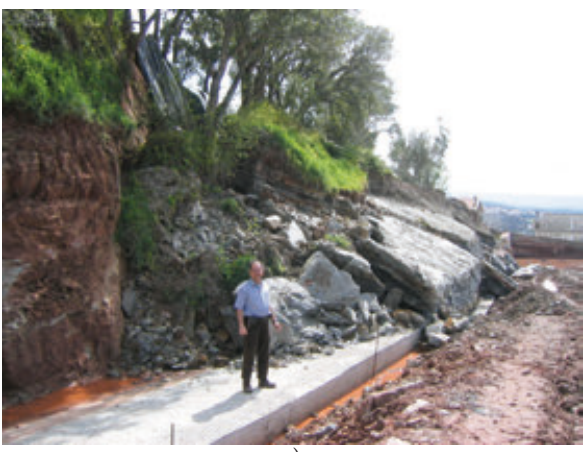

c)

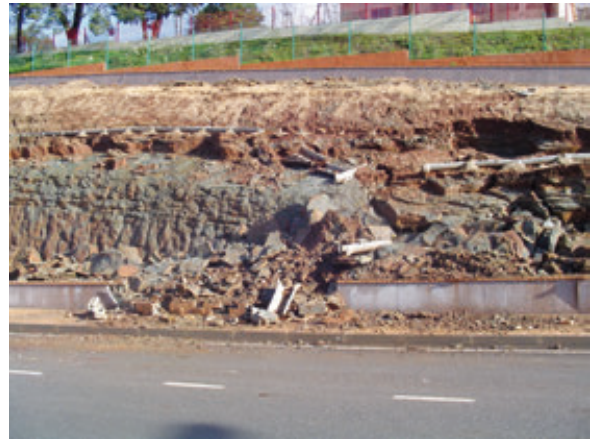

b)

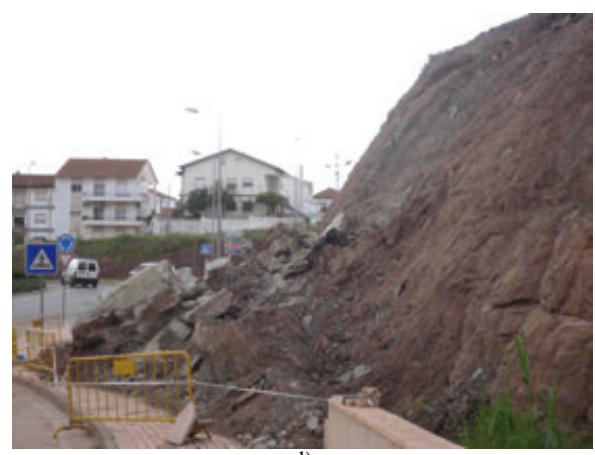

d)

Fig. 1 - Aspeto de algumas das instabilizaçôes ocorridas no Areeiro. a) Estrada a nascente da escola do Areeiro, em Março 2004; b) Talude da escola do Areeiro, em Dezembro de 2005; c) Urbanização da Quinta do Areeiro, em Março de 2006; d) Rotunda do Areeiro, em Abril de 2010.

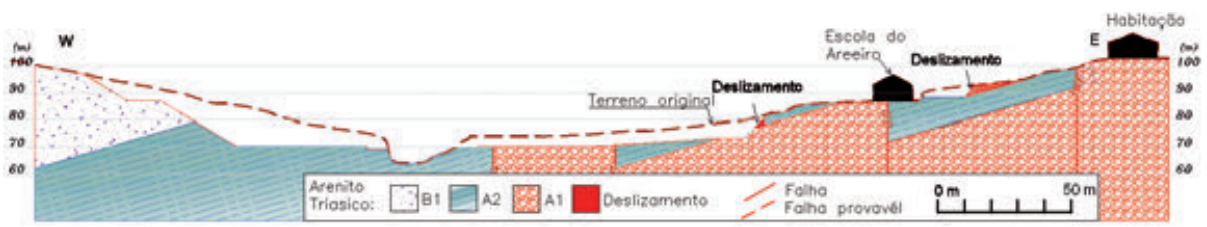

Fig. 2 - Perfil interpretativo orientado de oeste (W) para este (E) no vale do Areeiro. À esquerda situa-se a Quinta da Portela e à direita a zona do Areeiro. A1, A2 e B1 - termos do Grés de Silves segundo PALAIN

(1976).

Sabendo-se que as camadas de arenito mergulham genericamente para oeste, com pendores rondando $15^{\circ}$ a $16^{\circ}$, não parecia provável a ocorrência de qualquer problema de instabilização, numa formação essencialmente arenítica, que se caracteriza por apresentar ângulos de atrito elevados. Os pelitos (siltitos e argilitos) que se encontram intercalados nas bancadas areníticas em zonas condiconads estratigráficamente, apresentam uma espessura que varia entre $0,1 \mathrm{~m}$ e $0,3 \mathrm{~m}$ e têm superfícies de descontinuidade quase lisas a lisas (Fig. 3). As unidades areno-conglomeráticas possuem espessuras superiores às definidas pelos pelitos e as suas superfícies de 
descontinuidade são ligeiramente rugosas a quase lisas. A família principal das descontinuidades corresponde aos planos de estratificação das camadas areno-conglomeráticas e pelíticas.

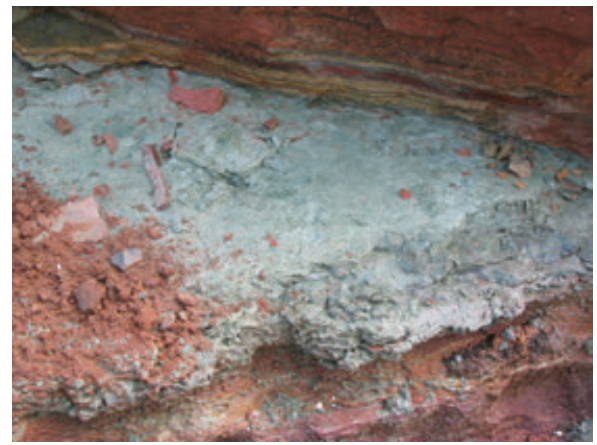

a)

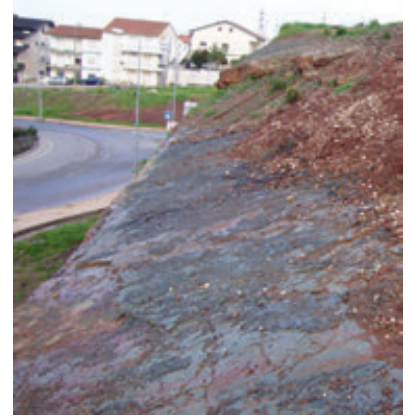

b)

Fig. 3 - Presença de pelitos intercalados nas unidades areno-conglomeráticas.

Considera-se que as características e dimensões das instabilizações foram essencialmente condicionadas pela geologia local, ao definir zonas, delimitados por falhas, em que as camadas pelíticas (silto-argilosas) intercaladas nos arenitos sofreram rotura pontual, ocasionando a queda dos taludes de escavação. A rotura das camadas dos pelitos resultou da sua baixa resistência ao corte, após a atuação dos processos de degradação desencadeados pela intervenção humana. A evolução das características dos pelitos, que sendo originalmente uma rocha branda, se transformam progressivamente num solo de baixa resistência ao corte, foi investigada recorrendo à realização de vários ensaios de laboratório, procurando determinar quer as características mineralógicas destes materiais, quer as suas propriedades físicas e mecânicas condicionantes da estabilidade.

\section{3 - Características das amostras intactas}

Os pelitos encontrados "in situ" possuem propriedades físicas que resultaram da evolução das condições geológicas desde a sua formação, tendo sofrido fortes tensôes verticais devido ao recobrimento e à diagénese, resultado a formação uma rocha branda.

Para avaliar as características físicas das amostras intactas, foram efetuados ensaios com o porosímetro de mercúrio, cujos resultados se apresentam na Tabela 1 . A escolha do porosímetro de mercúrio resultou da necessidade de utilizar uma técnica que náo destruísse a estrutura interna da amostra, que se sabia ser muito evolutiva em contacto com a água (ISRM, 2007). Para identificar a mineralogia dos pelitos foram realizados ensaios de Raios-X. Para a fração grosseira foram identificados quartzo, feldspato potássico, mica e vestígios de dolomite. $\mathrm{Na}$ fração fina, correspondente às argilas, foram identificadas a ilite como mineral dominante, a caulinite e interestratificados ilite-vermiculite (QUINTA-FERREIRA et al., 2011). 
Tabela 1 - Resultados dos ensaios com o porosímetro de mercúrio.

\begin{tabular}{lllllll}
\hline Amostra No & & A11-1 & A11-2 & A11-3 & A11-4 & A11-5 \\
\hline Área total dos poros & $\left(\mathrm{m}^{2} / \mathrm{g}\right)$ & 11.36 & 6.51 & 6.75 & 5.36 & 12.61 \\
Diâmetro médio dos poros & $(\mu \mathrm{m})$ & 0.031 & 0.042 & 0.033 & 0.049 & 0.028 \\
Peso volúmico seco $\gamma_{\mathrm{d}}$ & $\left(\mathrm{kN} / \mathrm{m}^{3}\right)$ & 20.79 & 21.81 & 22.56 & 22.11 & 20.80 \\
Peso volúmico real $\gamma_{\mathrm{s}}$ & $\left(\mathrm{kN} / \mathrm{m}^{3}\right)$ & 25.56 & 25.77 & 25.85 & 25.94 & 25.51 \\
Porosidade & $(\%)$ & 18.64 & 15.35 & 12.73 & 14.79 & 18.46 \\
\hline
\end{tabular}

\section{4 - Propriedades índice das amostras remexidas}

$\mathrm{Na}$ sequência da alteração e desagregação da rocha branda, devido à descompressão em presença da água, formam-se solos cujo comportamento condiciona grandemente a estabilidade dos taludes estudados. Para melhor conhecer as características destes solos invulgares foram caracterizadas três amostras remexidas (A11.1, A11.3 e A11.5) através da análise granulométrica e dos limites de consistência. As amostras colhidas foram secas e reduzidas a pó. Ao material destinado aos ensaios de consistência foi adicionada água e deixado repousar, por um período de 24 horas antes da realização dos ensaios. A Tabela 2 resume os resultados dos ensaios de consistência bem como do tamanho das partículas.

De acordo com a carta de plasticidade de Casagrande as amostras estudadas são classificadas como CL (argilas de baixa a média plasticidade). A atividade das amostras A11.1 e A11.5, com o valor próximo de 1, confirma os ensaios de Raios-X os quais indicam a ilite como mineral argiloso predominante. Para a amostra A11.3, a argila que possui é de alta atividade, no entanto apenas tem uma percentagem de $5 \%$ de argila.

Tabela 2 - Resultados dos ensaios de consistência e do tamanho das partículas.

\begin{tabular}{|c|c|c|c|c|c|c|c|c|}
\hline \multirow{2}{*}{$\begin{array}{l}\text { Amostra } \\
\text { No }\end{array}$} & \multicolumn{3}{|c|}{$\begin{array}{c}\text { Granulometria } \\
(\%) \\
\end{array}$} & \multicolumn{3}{|c|}{$\begin{array}{c}\text { Consistência } \\
(\%)\end{array}$} & \multirow[t]{2}{*}{ A } & \multirow[t]{2}{*}{ Classificação do solo } \\
\hline & Argila & Silte & Areia & $\mathrm{w}_{\mathrm{L}}$ & $\mathrm{w}_{\mathrm{p}}$ & IP & & \\
\hline A11.1 & 17 & 51 & 32 & 37,5 & 20,3 & 17,2 & 1,0 & \multirow{2}{*}{$\begin{array}{c}\text { Argila siltosa de atividade } \\
\text { intermédia }\end{array}$} \\
\hline A11.5 & 15 & 55 & 30 & 40 & 22,4 & 17,6 & 1,2 & \\
\hline A11.3 & 5 & 65 & 30 & 31 & 20,5 & 10,5 & 2,1 & Argila siltosa de atividade alta \\
\hline
\end{tabular}

\section{5 - Resistência ao corte}

Para a determinação da resistência ao corte foram realizados ensaios no aparelho de corte rotativo de Bromhead. A amostra tem uma forma anelar, uma altura de $5 \mathrm{~mm}$, um diâmetro interno de $70 \mathrm{~mm}$ e externo de $100 \mathrm{~mm}$, preenche o anel inferior, sendo cortada contra uma placa de bronze suficientemente rugosa para evitar o deslizamento na interface da placa com o solo, formando-se assim uma superfície de rotura no solo 
a escassos milímetros da interface. A carga normal é aplicada através da placa superior utilizando um sistema de pesos e alavanca formando uma razão de 10:1. O prato inferior roda a uma velocidade constante e o prato superior reage contra dois anéis dinamómetros aplicando um momento torsor à amostra. As deformaçóes verticais do anel superior podem ser medidas através de um defletómetro. O deslocamento horizontal é calculado através da medição da rotação angular. As amostras são preparadas com um teor em água próximo do limite de plasticidade, deixadas a uniformizar durante 24 horas e colocadas na cavidade anelar por pressão com os dedos e uma pequena espátula, evitando a retenção de ar. O solo em excesso é retirado, a superfície nivelada e o conjunto colocado no prato de rotação. $\mathrm{O}$ excesso de solo é utilizado para a determinação do teor em água inicial (Tabela 3).

A amostra foi consolidada por estágios para uma tensão de $400 \mathrm{kPa}$, e submetida ao corte até a condição residual ser estabelecida. A resistência máxima inicial obtida nesta primeira fase foi assumida como representativa da resistência ao corte na condição normalmente consolidada ou a volume constante. A resistência ao corte residual foi então sucessivamente determinada para tensôes normais inferiores, como se indica na Tabela 4.

Tabela 3 - Teor em água inicial dos solos ensaiados no corte rotativo.

\begin{tabular}{lccc}
\hline Amostra No & A11.1 & A11.3 & A11.5 \\
Teor em água inicial (\%) & 20,2 & 25,6 & 25,0 \\
\hline
\end{tabular}

Tabela 4 - Sequência de estágios utilizada nos ensaios de corte anelar.

\begin{tabular}{|c|c|c|c|c|c|c|c|c|}
\hline Estágio No & 节 & 1 & 2 & 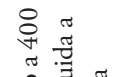 & $3^{\#}$ & 4 & 5 & 6 \\
\hline Tipo & 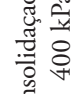 & $1^{\circ}$ corte & corte & 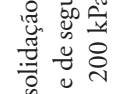 & corte & corte & corte & corte \\
\hline Tensão Normal (kPa) & نี & 400 & 200 & $\tilde{U}^{\tilde{E}}$ & 200 & 100 & 50 & 25 \\
\hline
\end{tabular}

Após a condição residual ter sido estabelecida no estágio 2, a amostra foi sobreconsolidada, consolidando-a sob uma tensão de $400 \mathrm{kPa}$ e descarregando-a novamente para a tensão de $200 \mathrm{kPa}$. A amostra foi novamente cortada à tensão de 200 $\mathrm{kPa}$, investigando-se o modo de corte de acordo com a proposta de LUPINI et al. (1981). Os resultados mostram um comportamento frágil no primeiro corte (Fig. 4) e um comportamento dúctil no estágio 3, o que sugere um modo deslizante, ou seja uma superfície de rotura com as partículas completamente orientadas na direção de corte.

Depois de uma superfície de corte formada por partículas orientadas na direção de corte, um processo de sobreconsolidação não origina um aumento de resistência devido à diminuição da porosidade.

A partir do estágio de corte inicial sob a tensão normal de $400 \mathrm{kPa}$ (Fig. 4) é possível obter o ângulo de resistência ao corte para a condição normalmente consolidada assumindo para a coesão o valor zero. Estes valores são apresentados na Tabela 5. 


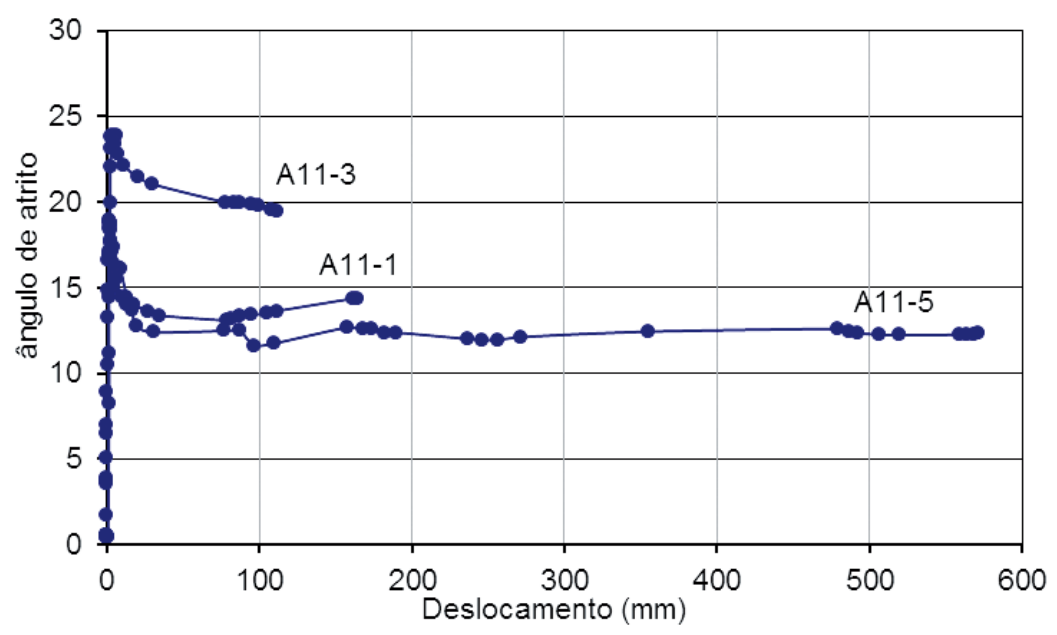

Fig. 4 - Primeiros estágios de corte com tensão normal de $400 \mathrm{kPa}$.

De acordo com LUPINI et al. (1981), as amostras A11-1 e A11-5 mostram um modo de corte deslizante.

Tabela 5 - Resistência normalmente consolidada e residual, expressa em termos de ângulo de atrito, considerando ausência de coesão.

\begin{tabular}{llccc}
\hline Amostra No & & A11.1 & A11.5 & A11.3 \\
\hline Ângulo de atrito de pico (o) & $\phi_{\mathrm{vc}}^{\prime}$ & 18,9 & 18,7 & 23,9 \\
Ângulo de atrito residual (o) & $\phi_{\mathrm{R}}^{\prime}$ & 13,0 & $12,0^{\circ}$ & $19,4^{\circ}$ \\
\hline
\end{tabular}

Na Fig. 5, apresenta-se a comparação entre a resistência ao corte residual obtida para os pelitos com os valores apresentados por LUPINI et al. (1981).
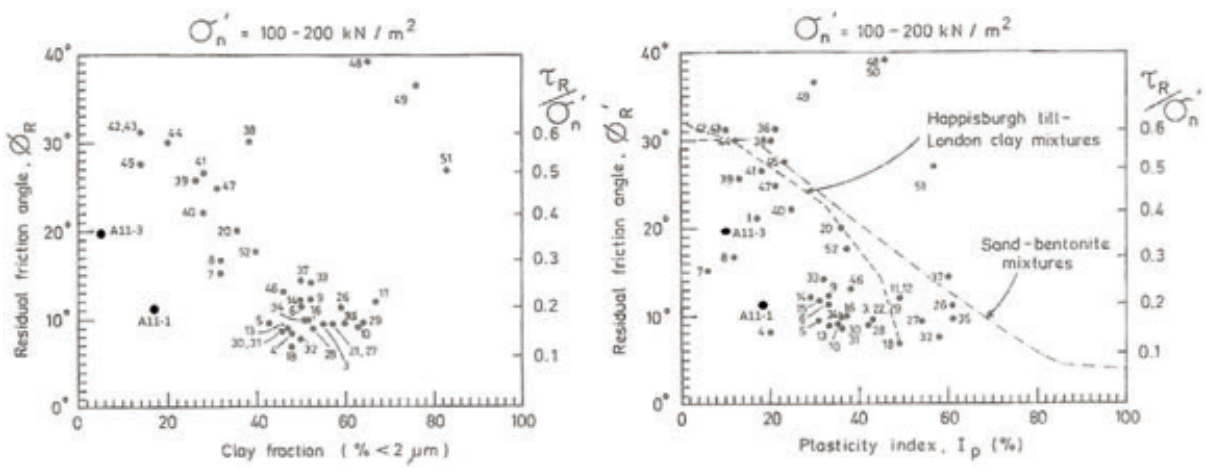

Fig. 5 - Comparação entre a resistência ao corte residual obtida para os pelitos com os valores de outros solos apresentados por LUPINI et al. (1981). 


\section{6 - Compressibilidade}

As amostras foram reduzidas a pó, tendo sido adicionada água destilada até teores em água próximos do limite de liquidez. De seguida as amostras foram moldadas no anel edométrico, tendo sido realizado o ensaio, duplicando as cargas, a cada 24 horas. Os índices de compressibilidade e de expansibilidade obtidos para as amostras A11-1 e A11-3 estão representados na Tabela 6. Considerando as porosidades de 18,5\% obtidas no porosímetro de mercúrio a partir das amostras indeformadas conclui-se que poderão ter existido tensôes efetivas máximas da ordem de $15 \mathrm{MPa}$ para justificar aquelas porosidades com base nos resultados dos ensaios edométricos.

\begin{tabular}{ccc} 
Tabela 6 - Índices de compressibilidade $\left(\mathrm{C}_{\mathrm{c}}\right)$ e de expansibilidade $(\mathrm{Cs})$ \\
\hline Amostra & A11-1 & A11-3 \\
\hline $\mathrm{C}_{\mathrm{c}}$ & 0,238 & 0,162 \\
$\mathrm{C}_{\mathrm{s}}$ & 0,041 & 0,024 \\
\hline
\end{tabular}

\section{7 - Análise da estabilidade}

De entre os vários taludes existentes na zona do Areeiro, foi escolhido o talude da rotunda do Areeiro para uma análise mais pormenorizada, procurando entender o comportamento do talude. Para a escolha deste talude foi relevante tratar-se do talude de escavação mais alto, com cerca de $12 \mathrm{~m}$ de altura e que sofreu vários episódios de instabilização no passado.

Analisou-se a estabilidade com base na análise cinemática recorrendo ao método de MARKLAND (1972), com o refinamento do HOCKING (1976), e ainda a análise do equilíbrio limite de uma rotura planar.

Para o método de MARKLAND (1972) mediram-se a direção, pendor e rugosidade de 176 descontinuidades, tendo a projeção estereográfica possibilitado a identificação de três famílias de descontinuidades principais: A) N24W;15ㅇW; B) N26W;67ºSW; C) $\mathrm{N} 55^{\circ} \mathrm{E} ; 82^{\circ} \mathrm{SE}$.

A estratificação corresponde ao sistema A e representa 55\% das descontinuidades medidas. As instabilizaçóes observadas ocorreram nesta família. Sendo o talude essencialmente constituído por arenitos, com ângulos de atrito acima de $35^{\circ}$, não há a possibilidade de ocorrer deslizamento por estes materiais.

Os pelitos intactos apresentam características de rocha branda com elevados ângulos de atrito. Com a execução das escavações ocorre a descompressão das faces expostas do maciço e a consequente degradação dos pelitos, dando origem a materiais terrosos. Os ensaios de laboratório mostraram que a resistência de pico dos pelitos degradados $\left(18,7^{\circ}\right.$ a $\left.23,9^{\circ}\right)$ é superior à inclinação da estratificação, pelo que de acordo com o método de MARKLAND (1972) e o refinamento de HOCKING (1976) não deveriam existir instabilizaçôes nestas circunstâncias.

Sabendo-se no entanto que as instabilizações dos taludes de escavação ocorrem essencialmente após períodos de chuva (QUINTA-FERREIRA et al., 2005, 2006), analisaram-se as condiçôes do equilíbrio limite de uma rotura planar conducentes à instabilização. Enquanto no tempo seco se desenvolvem tensóes de sucção (negativas) que estabilizam o talude, pelo contrário com a chuva acumula-se água nos terrenos, 
aumentando a tensão neutra. Por analogia com as instabilizações ocorridas, considerando um bloco com $8 \mathrm{~m}$ de comprimento por $2 \mathrm{~m}$ de espessura, com uma inclinação de $16^{\circ}$ da superfície de deslizamento numa camada de pelito alterado, um ângulo de atrito de pico de $19^{\circ}$ associado a uma pressão de água de apenas $0,4 \mathrm{~m}$ acima da superfície de deslizamento, é suficiente para reduzir o fator de segurança para um valor unitário, desencadeando a rotura do talude.

Os ensaios de laboratório permitiram concluir que as amostras remexidas, apresentavam um ângulo de atrito residual que podia descer aos $12^{\circ}$, justificando a fácil ocorrência de deslizamentos pela família A, após ser ultrapassada a resistência de pico na sequência de pequenos movimentos segundo a superfície de rotura, propiciados pela descompressão da face do talude.

\section{8 - Consideraçóes finais}

Analisam-se diversas situações de instabilização de taludes de escavação, ocorridas ao longo de cerca de 8 anos, na Formação da Conraria (base do termo A2) dos Grés de Silves (PALAIN, 1976), na zona do Areeiro em Coimbra. Procurou-se entender as causas das instabilizações, em situações geotécnicas que náo faziam antever problemas de instabilidade. Nos taludes afloram essencialmente arenitos siliciosos interestratificados com finas camadas de pelitos, mergulhando cerca de $16^{\circ}$ para oeste.

Fazendo uma análise comparativa dos dois lados do vale, Areeiro a este, e Quinta da Portela a oeste, foi possível concluir que a estrutura geológica, a geomorfologia e as características dos pelitos são fatores que influenciam a ocorrência dos deslizamentos. Estas condiçôes permitem a ocorrência de instabilizações segundo planos de reduzida inclinação para a face do talude, do lado do Areeiro, mesmo para taludes de escavação de apenas alguns metros de altura, enquanto no lado oposto do vale, na Quinta da Portela, taludes com mais de $20 \mathrm{~m}$ de altura se apresentam estáveis.

Com base nos ensaios de laboratório realizados concluiu-se que os pelitos terão sofrido no passado uma compressão da ordem dos $15 \mathrm{MPa}$, o que equivale aproximadamente à carga resultante da espessura do termo $\mathrm{A} 2$ dos Grés de Silves.

$\mathrm{O}$ ângulo de atrito, quer dos arenitos, quer dos pelitos intactos, é muito superior à inclinação das camadas, náo permitindo a ocorrência de deslizamentos segundo os planos das camadas. Verificou-se no entanto que os pelitos sofrem degradaçáo no tempo, quer devido ao alívio de carga resultante das escavaçôes efetuadas nos taludes, quer devido ao aumento da pressão de água.

O ângulo de atrito de pico dos pelitos degradados pode rondar $19^{\circ}$. No entanto como as tensóes de sucção são removidas com o aumento da saturação dos terrenos, calculou-se que uma coluna de água de apenas $0,4 \mathrm{~m}$ acima da superfície de corte cria condiçóes capazes de originar a rotura dos taludes.

Na situação atual, a zona da Escola do Areeiro e da rotunda do Areeiro são os locais que justificam maior preocupação, sendo conveniente efetuar a monitorizaçáo destes taludes, em especial nas épocas de maior pluviosidade. Considera-se conveniente a utilização de algumas medidas de estabilização, nomeadamente reperfilar os taludes, evitar a descompressão da face dos taludes, aplicando medidas de contenção, e efetuar a drenagem dos terrenos de modo a evitar a subida das pressóes neutras. 
A caracterização geológica, em conjunto com os ensaios de laboratório, permitiram entender os mecanismos de instabilização dos taludes do Areeiro. A reduzida inclinação dos planos de estratificação que originaram a instabilização, a presença de camadas de pelitos evolutivos e a ocorrência de precipitação intensa constituem os aspetos mais marcantes das instabilizaçóes.

Agradecimentos - Este trabalho foi financiado pelo Estado Português através da FCT - Fundação para a Ciência e a Tecnologia no âmbito do projecto PEst-OE/CTE/ UI0073/2011 do Centro de Geociências.

\section{Referências Bibliográficas}

AZERÊDO, A.C., DUARTE, L.V., HENRIQUES, M.H. \& MANUPPELLA, G. (2003) - Da dinâmica continental no Triásico aos mares do Jurássico Inferior e Médio. Instituto Geológico e Mineiro, 43p.

HOCKING, G.A. (1976) - Method for distinguishing between single and double plane sliding of tetrahedral wedges. International Journal of Rock Mechanics and Mining Science and Geomechanics, 13, p. 225-226

ISRM (2007) - The complete ISRM suggested methods for rock characterization, testing and monitoring: 1974-2006. Ulusay and Hudson (eds). ISRM Turkish National Group.

LUPINI, J.F., SKINNER, A.E. \& VAUGHAN, P.R. (1981) - The drained residual strength of cohesive soils. Géotechnique, 31(2), p. 181-213

MIRANDA, J., PINA, B., MATOS, V., CALHÔA, A.M., PENA DOS REIS, R. \& PIMENTEL, N. (2010) - Estudo das fácies de leque aluvial em afloramento do Triásico Superior de Coimbra. e - Terra, 21 ( 9), 4p.

MARKLAND, J.T. (1972) - A useful technique for estimating the stability of rock slopes when the rigid wedge slip type of failure is expected. Imperial College Rock Mechanics Research Reprints, 19, p. 1-10

PALAIN, C. (1976) - Une série détritique terrigène. Les “Grés de Silves”: Trias et Lias inférieur du Portugal. Memórias, Serviços Geológicos de Portugal, Lisboa. 25 (nova série), 377p

QUINTA-FERREIRA, M., LEMOS, L.L. \& PEREIRA, L.M. (2005) - Influência da precipitação na ocorrência de deslizamentos em Coimbra, nos últimos 139 anos. Geotecnia 104, p. 17-30

QUINTA-FERREIRA, M., LEMOS, L.L. \& PEREIRA, L.M. (2006) - Influência da precipitação nos deslizamentos e no comportamento dos pelitos do Triásico, em Coimbra”. 10 Cong. Nacional de Geotecnia. Sociedade Portuguesa de Geotecnia 1, p. 61-72.

QUINTA-FERREIRA, M., ANDRADE, P.S. \& SARAIVA, A. (2011) - Instabilidade de taludes de escavação no Areeiro, Coimbra. Simpósio Modelação de Sistemas Geológicos Homenagem ao Professor Manuel Maria Godinho, pp. 329-342. Coimbra, 15 de Janeiro de 2011.

SOARES, A.F., MARQUES, J. \& SEQUEIRA, A.. (2007) - Folha 19-D, Coimbra-Lousã, Carta Geológica de Portugal. Escala 1:50 000. INETI, Departamento de Geologia, Lisboa. 